\title{
Leituras fáusticas de Machado de Assis
}

\author{
Gilberto Pinheiro Passos ${ }^{1}$
}

\begin{abstract}
This article examines three novels by Machado de Assis, namely Dom Casmurro, Esaú e Jacó and Memorial de Aires, and aims to relate common, ordinary characters which reflect a changing Brazil to the Faust myth. This intertextual dialogue illustrates a way of looking at the unextraordinary, but still appealing, lives of these characters.
\end{abstract}

Keywords: Faust myth; Machado de Assis; Brazilian literature

Resumo: O presente artigo busca retratar o aproveitamento feito por Machado de Assis do tema fáustico, nos romances Dom Casmurro, Esaú e Jacó e Memorial de Aires, fazendo com que o mesmo conviva com figuras comuns, representativas de um Brasil em mudança. Desse modo, o diálogo intertextual exemplifica uma das maneiras de se caracterizar a vida estreita das personagens que nem por isso, deixam de ser dignas de interesse.

Palavras-chave: Mito fáustico; Machado de Assis; literatura brasileira

\section{Abrasileirando o tema}

Na sua busca de diálogo com as literaturas européias, Machado de Assis escolhe autores que, além de representarem alguns dos pontos mais altos da arte ocidental, participam da economia narrativa de cada obra em que se inserem e conseqüentemente - do desenvolvimento da literatura brasileira, já que, desde muito cedo, ou seja, quando da publicação de “Instinto de Nacionalidade”(1873), o autor manifesta nítida intenção de se valer do pecúlio universal para estofar nossa produção. É nesse contexto de conjugação de refinado gosto, frutífero diálogo textual e busca de universalização, que o tema de Fausto vem à tona, lastreado na obra de Goethe.

Já em Dom Casmurro, as figuras espectrais do início do poema dramático alemão são invocadas para dar fim ao dilema do narrador: o que escrever, a quem se referir. Bentinho, no seu refinamento de autor culto, precisa de um dado a mais para sua narrativa da vida conjugal. Preso ao passado, obcecado por ele, põe-se a campo para enodoar as figuras de Escobar e Capitu, que jaz morta na Suíça, assim como o filho “adulterino”, morto em Jerusalém. O passado se configura para sempre perdido, salvo

\footnotetext{
${ }^{1}$ Professor titular do Departamento de Letras Modernas da Faculdade de Filosofia,Letras e Ciências Humanas da Universidade de São Paulo.Endereço eletrônico: gipipas@uol.com.br
} 
por meio de sua evocação silenciosa e acabrunhante feita pelo único sobrevivente do drama, ainda e sempre às voltas com os seus ciúmes.

Iniciar a história do único e grande amor da vida é tarefa que não se faz sem certos cuidados literários e um deles se evidencia desde o ínício: Capitu não é só Capitu, mas também Manon Lescaut ou Carmen, pois deve lembrar dados da Mulher Fatal. Para tanto, a literatura anterior se faz presente, no sentido de incluir a leitura da obra numa ciranda que insere a esposa no quadro de figuras femininas enganadoras e indignas.

Para esse bacharel culto, não há escapatória: o libelo acusatório deve ser convincente, contendo fatos, alusões e citações probantes. Nada melhor do que se valer da cumplicidade do leitor, ser irônico e, em muitos momentos, mostrar-se mordaz e patético em sua “certeza” ou “cegueira” relativa aos fatos, valendo-se do código literário partilhado com seu destinatário. Daí a presença do Fausto, com suas sombras a evocar as lembranças do passado: “Talvez a narração me desse a ilusão, e as sombras viessem perpassar ligeiras, como ao poeta, não o do trem, mas o do Fausto: Aí vindes outra vez, inquietas sombras...?” (Assis 1975a: 69).

A tarefa do poeta alemão é de grande monta: relembrar entes queridos e rememorar sua obra anterior são efeitos das silhuetas indecisas que promanam das brumas e vapores. Aparentemente, a lembrança do narrador brasileiro relativa ao mito de Fausto, cujo drama está para ser iniciado, se espelharia num monumental trabalho a ser realizado. Organizá-lo, galvanizando sua potencialidade dramática é a grande aposta. O vezo machadiano da "minimização do conflito" e "apequenamento da personagem”, no entanto, se faz mais uma vez presente, pois Bentinho não se aprofundará na noite dos tempos em que viveu a personagem alemã, nem buscará tematizar a circularidade do tempo, que faria do velho Fausto um jovem capaz de amar Gretchen. Sua narrativa é muito menos encorpada, malgrado a força da temática religiosa que envolve a vida do filho da endinheirada Dona Glória.

Para cada uma das grandes obras citadas, notamos a correspondente redução aos limites dos habitantes do Rio de Janeiro, graças à lição de José de Alencar, no posfácio ao romance Senhora: “(...) fizeste ao autor o maior elogio dizendo que ele talha os seus personagens no tamanho da sociedade fluminense. É justamente por esse cunho nacional que eu o aprecio.” (ALENCAR 1994 : 186)

Há uma escala de valores e situações a ser mantida. As sombras servem para fazer renascer a narrativa miúda do drama doméstico de um burguês carioca do século XIX. Minimiza-se o conflito e a morte altissonante, que ronda o par central da obra 
alemã não se verá confirmada, na obra brasileira, laicizando-se e atingindo apenas Capitu, que, burguês e cordatamente, morre na Suíça, ao passo que Bentinho, refestelado em sua condição de proprietário e dono da voz narrativa se põe a campo para se tornar um "miúdo” escritor.

Não pára por aí o narrador machadiano, pois sua produção busca acrescentar de modo insofismável a tentativa de expressão da realidade histórica brasileira, vista não do ângulo das grandes figuras, mas das pequenas, imersas nas preocupações de uma vida sem grandiosidade, como é a lição do Realismo mais refinado, consignando-se a fruição, por parte dos leitores, de seres cuja configuração complexa e profunda vai perfeitamente de par com tal apequenamento da personagem e minimização dos conflitos ${ }^{2}$.

\section{Um diplomata atilado}

Em Esaú e Jacó e Memorial de Aires, o bruxo do Cosme Velho buscou retratar uma personagem dividida entre origem brasileira e andanças pelo mundo ${ }^{3}$. O diplomata José da Costa Marcondes Aires, o Conselheiro Aires, representa uma consciência em que a realidade de nosso país se mescla às lições aprendidas ao longo da carreira, em terras estrangeiras.

Tal estado de coisas pode ser resumido no fato de afirmar ter visto tudo por várias línguas, ou seja, ter sabido identificar e “traduzir” situações das mais diversas. Retornando ao Brasil, em licença (Esaú e Jacó) ou como aposentado (Memorial de Aires), Aires busca se inteirar dos acontecimentos nacionais, uma vez que suas longas ausências acabam por fazer dele um quase “estrangeiro” entre nós. Freqüentando famílias ricas ou de alguma posse, pertence à nata da sociedade fluminense e, graças ao tempo de que dispõe, escreve seu diário, em que reflexões baseadas em ironia fina e percuciente curiosidade dão conta de problemas íntimos (namoros, heranças) e questões político-sociais (Abolição, República, Encilhamento).

\footnotetext{
${ }^{2}$ Em significativo eco intertextual, algumas páginas adiante, Bentinho apresenta a teoria do tenor Marcolini sobre a vida como uma composição operística feita por Deus (libreto) e pelo Diabo (partitura). É o acordo de vontade entre os dois que permite a "representação", ou seja, a existência.

${ }^{3}$ Para maiores esclarecimentos sobre o uso da cultura literária ocidental pelo Conselheiro Aires, V. PASSOS, Gilberto Pinheiro - As sugestões do Conselheiro/ A França em Machado de Assis: Esaú e Jacó e Memorial de Aires .São Paulo, Nankin Editorial, 2008.
} 
A representação diplomática (com todos os seus matizes semânticos) dá lugar à representação do Brasil, visto não do ângulo dos grandes atores da história, mas do prisma dos quase anônimos, que participam, como coadjuvantes, da cena nacional. Em escala mínima, portanto, converge para sua pena a série de questões levantadas pelas datas fundamentais para a história do país, realinhadas pela órbita de interesses particulares, como a de uma personagem riquíssima, o banqueiro Santos, que, em Esaú e Jacó acorre à casa do Conselheiro, preocupado com os rumos econômicos que a República poderia tomar. Aires, prudente, conciliador e cultivado em matéria política, enuncia a verdade histórica inescapável: “Nada se mudaria; o regímen, sim, era possível, mas também se muda de roupa sem trocar de pele. Comércio é preciso. Os bancos são indispensáveis.” (Assis 1975b:188)

Elementos tirados da obra alemã concorrem, de modo particular, para caracterizar não apenas a principal personagem feminina, a doce e inexplicável Flora, mas também pontuar o hábito do narrador machadiano de ancorar seu diálogo com grandes obras, por meio de citações ou referências:

ANDA, FLORA, ajuda-me citando alguma cousa, verso ou prosa, que exprima a tua situação. Cita Goethe, amiga minha, cita um verso do Fausto, adequado: Ai, duas almas no meu seio moram!

A mãe dos gêmeos, a bela Natividade podia havê-lo citado também, antes deles nascerem, quando ela os sentia lutando dentro em si mesma:

Ai, duas almas no meu seio moram!

Nisto as duas se parecem, - uma os concebeu, outra os recolheu. Agora, como é que se dá ou se dará a escolha de Flora, nem o próprio Mefistófeles no-lo explicaria de modo claro e certo. O verso basta:

$\mathrm{Ai}$, duas almas no meu seio moram!

Talvez aquele velho Plácido, que já deixamos nas primeiras páginas, chegasse a deslindar estas outras. Doutor em matérias escuras e complicadas, sabia muito bem o valor dos números, a significação dos gestos não só visíveis como invisíveis, a estatística da eternidade, a divisibilidade do infinito. (Assis 1975b: 217)

Como se vê, uma frase de Fausto e o próprio Mefistófeles se fazem presentes na trama em que dois gêmeos, Pedro e Paulo, um monarquista e outro republicano, brigam desde o útero materno e se apaixonam por Flora, cuja indecisão é elemento fundamental no desenvolvimento do enredo. Além disso, em singela “identificação” com o necromante alemão, temos a figura do espírita Plácido, personagem secundária que, em provável paródia, pontua mais uma vez a necessidade de se explicarem os desencontros 
e desentendimentos entre os rapazes, assim como a esperada decisão da moça por um dos enamorados.

Convém notar que o romance começa exatamente pela ida da mãe dos rapazes a uma região algo erma da cidade para ouvir uma vidente, a cabocla do Castelo, que predizia o futuro e saberia lhe contar o futuro dos filhos. Em seguida, o marido busca consultar Plácido, adivinho de longas barbas brancas e camisola. Crendice popular e espiritismo preparam o texto para a irrupção da figura de Fausto.

O texto brasileiro opera a fusão paródica do popular com o erudito, não sem alertar o leitor, pois como observa a voz narrativa, a leitura deverá ser feita como se observássemos uma "partida entre pessoa e pessoa, ou mais claramente, entre Deus e o Diabo.” (Assis 1975b: 91). Não se pode, nesse contexto da obra, desprezar a hipótese de o texto machadiano estar se referindo à aposta inicial do Fausto, porém com inegável mudança de sentido, pois que absolutamente incorporado à eterna dissensão entre Pedro e Paulo.

Agora, podemos buscar entender o aproveitamento do verso alemão, que aliás, consta do manuscrito de Esaú e Jacó: “Zwei Seelen wohnen, ach! In meiner Brust!" (Assis 1975b: 217). Presente na parte inicial do Fausto e integrando sua caracterização, aponta para o caráter dúplice da personagem, que oscila entre o céu e a terra, os reclamos da carne e o encanto dos espaços infinitos, na busca da eternidade. Trata-se de de uma dicotomia de magna expressão, algo como o destino do ser humano dilacerado entre a satisfação dos apetites terrenos mais imediatos e uma ascese redentora.

A minimização dos conflitos mais uma vez atenua a força cruel da fonte alemã, pois o texto brasileiro redimensiona a questão expressa por Goethe. Na verdade, Machado busca incorporar a fonte erudita ao dilema individual, inteiramente particular, da moça sonhadora, que abriga dois amores/almas em seu peito e, de modo ainda mais raso, embora sutil, o drama da mãe que carrega, no útero, os gêmeos.

A força dos versos alemães vem, também, do fato de - na peça - estar para ocorrer o encontro de Fausto com Mefistófeles. O destino da personagem se perfaz e os versos citados servem como resumo e ponto de apoio do desenvolvimento da trama, no que diz respeito a sua futura perdição. Nesse ponto, convém repeti-lo, o trabalho do narrador brasileiro é acenar com a grandiosidade da fonte alemã e obrigá-la, em sua faina intertextual, a se inserir - ainda que guardando dados do sentido original - em nova órbita de sentidos e intenções. 
O dado metafísico de Fausto cede lugar ao prosaico amor de uma jovem burguesa do século XIX e, ao mesmo tempo, ao conflito de dois irmãos, que, embora acirrado, não os leva à morte ou ao descrédito. É essa flexibilização do sentido primeiro da obra que mostra o trabalho de adaptação do texto brasileiro. Mefistófeles nos interessa, nesse momento, pois o narrador não deixa de consignar a qualidade marcante do demônio, isto é, sua astúcia e capacidade de penetração, consideradas mais profundas que as de Aires, como se lê em trecho de seu memorial, reproduzido em Esaú e Jacó e motivado pelo fato de o Conselheiro não poder penetrar o enigma de Flora: "Que o Diabo a entenda, se puder; eu, que sou menos do que ele, não acerto de a entender nunca." (Assis 1976: 179)

O drama faustiano merece, ainda, um verdadeiro apólogo, em que se conta, de modo algo burlesco, a história de um frade capuchinho e um mendigo que tingiam suas barbas, suscitando comentários:

Or, bene, para falar como o meu capucho, por que é que este e o maltrapilho voltaram do grisalho ao negro? A leitora que adivinhe, se pode: dou-lhe vinte capítulos para alcançá-lo. Talvez eu, por essas alturas, lobrigue alguma explicação, mas por ora não sei nem aventuro nada. Vá que malignos atribuam a frei *** alguma paixão profana; ainda assim não se compreende que ele se descobrisse por aquele modo. Quanto ao maltrapilho, a que damas queria ele agradar, a ponto de trocar alguma vez o pão pela tinta? Que um e outro cedessem ao desejo de prender a mocidade fugitiva, pode ser. $\mathrm{O}$ frade, lido na Escriptura, sabendo que Israel chorou pelas cebolas do Egipto, teria também chorado, e as suas lágrimas caíram negras. Pode ser, repito. Este desejo de capturar o tempo é uma necessidade da alma e dos queixos; mas ao tempo dá Deus habeas-corpus.(Assis 1975b: 109)

A volta no tempo, representada pela barba negra, finca suas raízes num motivo fundamental, que retoma o da personagem alemã: os reclamos do sexo, segundo a sugestão do narrador, que se apóia significativamente no substantivo "malignos" para matizar a hipótese. Presa ao drama dos indivíduos, a relação com Fausto aponta a brevidade do tempo, a urgência de amores outonais e também a pouca eficácia do intento. Sobrevinda a morte do mendigo, ou passados nove meses para o frade, nada mais resta da falsa juventude “estampada” no rosto. Haveria algo de ridículo na atitude dos dois, desde que vista de fora, a partir do ângulo de um narrador que não os julga, nem condena, apenas os contempla com o olhar dos que se permitem ser, aparentemente, infensos a essa espécie de logro. 
No entanto, o jogo com a instituição jurídica do "habeas-corpus" pode ser compreendido de modo duplo. Deus concede ao tempo a liberdade para que use de seu corpo, embora ele não o tenha. Contudo, sua passagem e o império que exerce sobre os seres se percebem na destruição implacável do humano, permitindo o outro sentido: que o tempo tenha, por metonímia, o corpo dos seres, destinados à decadência paulatina.

Se atentarmos mais uma vez para o fato de que a instância instauradora da narrativa é justamente o Conselheiro Aires, vítima confessa e consciente do mesmo logro a atingir o capuchinho e o maltrapilho, e que faz viagens à Europa para recuperar forças, estaremos diante de um desdobramento da consciência do narrador, que pode se ver refletido em seus apólogos zombeteiros.

\section{Um diplomata enamorado}

Nosso Conselheiro, cujo diário vai se transformar no Memorial de Aires, aprofunda nele o seu encanto pela cultura alemã, conforme se pode depreender da leitura do romance. Para relatar a crescente paixão que unirá Fidélia (flagrante jogo com os nomes Fidélio/Fidélia, em subterrânea alusão à opera de Beethoven) e Tristão (sugestivo prenome wagneriano) vai-se valer do poeta Gottfried August Bürger (17471794), autor da então conhecidíssima balada pré-romântica "Lénore”, da qual nosso narrador extrai um fragmento de verso citado em francês: "Les morts vont vite", correspondente ao alemão “(...) die Toten reiten schnell”, além de fazer referência à batalha de Sedan, palco da derrota dos franceses frente aos prussianos, em 1870.

Para o presente artigo, fiquemos com os aspectos de nosso tema constantes nessa obra. Comecemos pelo entrecho, que nos remete à aposta entre Aires, com seus sessenta e dois anos e sua irmã, Rita, sobre o possível casamento do diplomata com a jovem viúva Fidélia, que tinham encontrado no cemitério, durante uma visita ao túmulo da família. O narrador, envolvido pela cultura européia, nos conta, então, sua atitude:

- Mana, você está a querer fazer comigo a aposta de Deus e do Mefistófeles; não conhece?

- Não conheço.

Fui à minha pequena estante e tirei o volume do Fausto, abri a página do prólogo no céu, e li-lha, como pude." (Assis 1975c: 70)

De uma aposta de tal monta passamos a um pequeno jogo de dois irmãos algo bonachões, propiciando o aflorar do tema da metamorfose proposta pela obra de 
Goethe, com sua sugestão da força e do retorno da juventude, motivos a que vai se acoplar a dimensão ampla de uma constante, na pena do narrador, a passagem do tempo. Este não volta, fustigando corpos, sentimentos e lembranças.

A relativização do amor de Fidélia pelo marido morto se faz graças ao interesse de Aires por ela. A perspectiva faustiana, agindo sobre ele, predispõe o leitor para a mudança da personagem feminina, já que o diplomata a sugere:

Rita contou-me então alguma cousa da vida da moça e da felicidade grande que tivera com o marido, ali sepultado há mais de dous anos. Pouco tempo viveram juntos. Eu, não sei por que inspiração maligna, arrisquei esta reflexão:

- Não quer dizer que não venha a casar outra vez. (Assis 1975c : 70)

A ponderação é tanto mais eloqüente pelo fato de ser feita à irmã e confidente, no nível da trama, embora, no tocante ao campo intertextual, se configure onomástica e sintomaticamente presa ao tema fáustico, já que temos em "Rita" o diminutivo de Margarida, nome com que se traduz "Gretchen". É como se ele rondasse o narrador e não lhe desse saída, salvo se deixar possuir pelo sentimento temporão, estimulado pela possível contradição de um nome (Fidélia), sua juventude e beleza. Fechando o círculo, temos a origem da inspiração: maligna, mefistofélica.

Cumpre aqui ressaltar que, ao longo do romance, a gama semâtica relativa ao demônio reaparece por várias vezes, carreando sentidos novos, em caso de leitura a partir do tema, até mesmo para algumas expressões populares. Assim, vamos encontrar um índice da rivalidade entre Aires e Tristão, um mês antes de sua volta de Lisboa, aonde fora morar ainda adolescente, na expressão pouco diplomática: "Leve o diabo tal filho."(Assis 1975: 113), utilizada por causa do interesse desmedido de sua madrinha, Dona Carmo, pelo afilhado. Ela e o marido, Aguiar, devotam afeição profunda tanto a Tristão quanto a Fidélia, cogitando, naturalmente, de os manter no Brasil, para - ainda que vicariamente - encontrar continuidade para seus corpos já velhos. O interesse de Aires, faustianamente "enamorado" se irmana ao diabo, pois se Mefistófeles se encarregasse de Tristão, talvez o narrador tivesse alguma esperança de êxito.

Admirador confesso da maledicência de certa personagem maldosa, Dona Cesária, usa o subterfúgio da graça existente nas críticas feitas por ela para reportá-las através da adjetivação própria ao demônio, figura fundamentalmente zombeteira, na peça de Goethe : "Não escrevo porque seja verdade o que Dona Cesária me disse, mas por ser maligno."(Assis 1975c: 186) 
Faustianamente desenganado, desculpa-se perante o leitor pelo fato de não desmentir o mal que a referida personagem propala, utilizando, em consonância com o "maligno", uma expressão popular que se renova, em seus liames com o tema: “Tudo isto considerado, e mais a hora, a viagem curta, e a presença do marido, que diabo ganhava eu em desfazer o que ela dizia?” (Assis 1975c: 187).

Tornado público o romance entre Tristão e Fidélia, ambos podem se permitir certo encantamento recíproco, diante dos convivas da família Aguiar, não sem um singular comentário de Aires, no qual a oposição entre o céu (vitorioso?) e os demônios (um deles, pelo menos, sustenta Fausto/Aires em seus ardores) redimensiona outra expressão popular:

Não me pareceu menos que o céu os animava e que eles nos mandavam a todos os diabos, a mim e aos três velhos, e aos pais de Tristão, aos paquetes, às malas. (ASSIS 1975c: 193).

O desaguadouro natural só poderia ser a própria figura de Mefistófeles que, segundo Aires, o aquinhoa com o especial talento de saber dividir, com gentileza, seu interesse:

Eu, com a arte que o Diabo me deu, divido a atenção entre a mãe e os dois filhos para concertar a cortesia e a curiosidade, e ambas saem satisfeitas do meu gesto.(AsSIS 1975c: 173)

A expressão colhida na linguagem do povo repropõe a ambigüidade que preside ao estilo do Conselheiro, graças ao fato de "Diabo", no exemplo seguinte, também vir grafado com letra maiúscula, embora pertencendo, na origem, à veia popular. Isso faz com que possa ser entendida de forma mais ampla, uma vez que por oposição ao enlevo celestial trazido à vida de Tristão pela noiva, a carreira política corresponderia a mais um sortilégio: "(...) todo ele é Fidélia, e bem pode mandar a cadeira das Cortes ao Diabo, se a noiva lho pedir." (Assis 1975c: 202)

A mesma Dona Cesária, revela certa bondade, quando, então, o narrador observa:

O alvoroço e doçura com que falou à outra compensou em grande parte o mal que me dissera dela, e por outra maneira confirmou o que lá pensei uma vez (e não sei se escrevi) sobre a propriedade deste mundo. Deus vencia aqui o Diabo, com um sorriso tão manso e terno que faria esquecer a existência do imundo consócio.(Assis 1975c: 204) 
Conforme podemos perceber, duas pespectivas se fundem: de um lado, conhecemos o quanto o tema de Fausto se torna próximo do narrador, contaminando até o nome de sua irmã e, por outro, temos um alvo para a nova corporificação fáustica, representada pelos dois brasileiros. Ela se concretiza, no domínio da trama, pela suposição, feita por Rita, do casamento de Aires com Fidélia, logo negado por ela mesma. Sintomaticamente, a falsa juventude do Conselheiro comparece, no nível textual, e os irmana ainda uma vez: "- Com os meus sessenta e dous anos? -Oh! não os parece; tem a verdura dos trinta." (Assis 1975c: 70)

Se Margarida representa a vítima da falsa mocidade de Fausto, aqui Rita ocupa um papel ao mesmo tempo oposto e tangencial. O pretenso rejuvenescimento fraterno servirá para estofar a trama. Por se querer "amado" de Fidélia, Aires experimentará ainda maior prazer em lhe seguir os passos. Além disso, Rita rejuvenesce, metaforicamente, o marido, não só por consignar-lhe metonimicamente seu corpo (uma vez que depositou no caixão uma mecha de seu cabelo), para sempre moço, como também por impedir, graças à lavagem do túmulo, que sua morte date de muito tempo. Preservando-a do envelhecimento e desafiando a morte, a oferenda torna-a agente singular da relação fáustica. Seu devotamento ao passado - que não quer remoto, mas de véspera - a enche de juventude, o que lhe possibilita tornar mais jovem o narrador.

Além da presença constante do diabo e suas figurações idiomáticas, assim como a caracterização oblíqua de Rita em relação ao tema, encontramos, portanto, Aires, leitor confesso do Fausto, “remoçado" e pronto para encarnar, ainda que pálida e simuladamente seu papel. Atributos não lhe faltam: homem viajado, o que o aproxima da personagem alemã, se mostra culto, prezando a tradição literária, de que faz largo uso.

O texto do diplomata busca a fonte de um tempo circular, que elidiria a velhice e possibilitaria não apenas a volta à juventude, mas também recriar a tradição ficcional, dado importante a ser considerado, no encontro entre os dois textos: a obra de Goethe se “renova”, porque entregue, de modo insuspeitado, a uma temática algo diferenciada, fazendo parte de uma literatura nova e de outra latitude. A mocidade, vencedora, refaz a força do tempo linear, obliterando a circularidade, ou seja, reinstitui de modo firme a inexorável seqüência a ser respeitada pelos jovens e velhos.

Desse modo, o fim do romance repropõe a preeminência do novo, o vigor do futuro que contém em si a força destruidora do mundo supostamente caduco; os Aguiares, tais como Filémon e Baucis, os dois velhos hospedeiros pobres, dedicados e 
leais, oriundos da pena de Ovídio e retomados por Goethe em seu segundo Fausto, tendem à eliminação, em vista de interesses renovadores e modernizantes. Os dois jovens, quase filhos do casal Aguiar, se casam e abandonam o Brasil e os "pais", deixando-os entregues à própria sorte e à velhice sem continuidade. Desolados, asssim os encontra o Conselheiro, na última visita que lhes faz:

Ao fundo, à entrada do saguão, dei com os dous velhos sentados, olhando um para o outro. Aguiar estava encostado ao portal direito, com as mãos sobre os joelhos. Dona Carmo, à esquerda, tinha os braços cruzados à cinta. Hesitei enttre ir adeante ou desandar o caminho; continuei parado alguns segundos até que recuei pé ante pé. Ao transpor a porta para a rua vi-lhes no rosto e na atitude uma expressão a que não acho nome certo ou claro; digo o que me pareceu. Queriam ser risonhos e mal se podiam consolar. Consolava-os a saudade de si mesmos. (Assis 1975c: 219)

Como se pode notar, os dois velhos não são eliminados da vida, mas da continuidade dela, ou seja, da possibilidade de gozarem a mocidade que os dois jovens encerram. A "saudade de si mesmos" vai além do mero aspecto pessoal, embora lhe esteja indissoluvelmente ligada, pois mergulha na continuidade do fio da história humana, no qual as gerações devem se suceder, sem se eternizar. Minimizado o conflito e apequenadas as personagens em relação à obra-fonte, nem por isso o diálogo com o grande marco da literatura ocidental se mostra menos frutífero. Sintomaticamente, um Aires/Fausto, sem a possibilidade de nova juventude, mas ocupado em ser escritor, pode contemplar em todos os três a negação mesma de sua inserção no futuro.

\section{Um autor crítico}

Qualquer que seja a máscara de que se vale nosso autor, sempre reponta a figura do bruxo do Cosme Velho, vigilante propulsor da literatura brasileira. Seja sob o nome de Bento Santiago ou Conselheiro Aires, uma preocupação: retratar o Brasil que se oferecia a seus olhos, um país urbano, caminhando para certos marcos da modernidade: a abolição da escravatura e a proclamação da república.

É nesse cenário que se movem as personagens variadas com quem convive um diplomata culto, cioso de sua vivência estrangeira, a ponto de buscar remédio para doenças em estações termais de nome e localização européia: 
Aires voltava da Europa, aonde fora com promessa de ficar seis meses apenas. Enganou-se; gastou onze (...). Ele fora a pretexto de águas, e, por mais que the recomendassem as do Brasil, não as quis experimentar. Não estava acostumado às denominações locais. Tinha esta impressão que as águas de Carlsbad ou Vichy, sem estes nomes, não curariam tanto. (ASSIS 1975b: 275)

Perfazendo o círculo que engloba realidade nacional e, ao mesmo tempo, possibilidade de expressão estrangeira, temos o tema fáustico a colorir a indecisão de Flora em Esaú e Jacó e o renascimento para o amor de Fidélia em Memorial de Aires. Machado de Assis cunha uma personagem especialmente talhada para tal tipo de associação, incutindo-lhe cultura e, ao mesmo tempo, o relativismo que caracteriza os que conhecem muitas culturas e sabem dar o devido valor à pluralidade de pensamentos e crenças: daí a escolha de um diplomata.

Aires traz à baila não apenas o fato bruto, haurido no contato com a vida brasileira, mas a sua caracterização diminuída, graças ao descompasso entre a fonte européia, Fausto, e a vida sem grandiosidade de personagens como Fidélia ou Flora. No entanto, nosso Conselheiro sabe que, nem por serem menores, os dramas domésticos deixam de ter importância, sobretudo se examinados por vários ângulos, donde o relativismo de que falamos. Não é apenas a opinião de Pedro, monarquista convicto que conta, mas também a de seu irmão, Paulo, republicano de primeira hora. Do mesmo modo, se os velhos Aguiares representam o arcaico, Fidélia e Tristão encarnam o novo, que precisa se impor. Todos os pontos de vista merecem ser ouvidos e realçados.

Para não encerrar os acontecimentos brasileiros no quadro estrito do localismo e, ao mesmo tempo, configurar uma dimensão humana mais abrangente ao dado nacional, mister é trabalhá-los à luz da tensão que o recurso às fontes envolve. O tema da obra alemã engloba o ente que se desloca no espaço, o viajante culto e cosmopolita e, na mesma medida, contempla a busca do tempo circular, de que o amor temporão é a mais dramática realidade.

Desse modo, representação do país por um brasileiro, com olhar “estrangeiro” o qual sabe ir além do mero encanto de Fidélia para alçar seu interesse à evocação do Fausto, eis aí um aproveitamento particular da circulação literária que apresenta insuspeitados encontros e sentidos “nunca dantes navegados”. 


\section{Referências bibliográficas}

AlenCAR, José de. Senhora/Iracema. São Paulo, Editora Scipione, 1994.

Assıs, Joaquim Maria Machado de. Dom Casmurro. Rio de Janeiro, Civilização Brasileira; Brasília, INL, 1975 (Edições críticas de Machado de Assis, v.12), indicado no texto como 1975 a.

Assıs, Joaquim Maria Machado de. Esaú e Jacob. Rio de Janeiro, Civilização Brasileira: Brasília, INL, 1975. (Edições críticas de obras de Machado de Assis,v.15), indicado no texto como 1975b.

Assis, Joaquim Maria Machado de. Memorial de Aires. Rio de Janeiro, Civilização Brasileira; Brasília, INL, 1975. (Edições críticas de Machado de Assis,v.10), indicado no texto como 1975c.

Passos, Gilberto Pinheiro. As sugestões do Conselheiro/ A França em Machado de Assis: Esaú e Jacó e Memorial de Aires. São Paulo, Nankin Editorial, 2008. 